\title{
A direita radical 'bolsonarista': da aporofobia à defesa da memória de regimes de exceção
}

The radical right of Jair Bolsonaro: from aporophobia to the defense of the memory of exception regimes

La droite radicale de Jair Bolsonaro: de l'aporophobie à la défense de la mémoire des régimes d'exception

La derecha radical de Jair Bolsonaro: de la aporofobia a la defensa de la memoria de los regímenes de excepción

\section{Edson Dalmonte e Priscilla Dibai}

\section{(2) OpenEdition}

\section{Journals}

\section{Edição electrónica}

URL: http://journals.openedition.org/ideas/6895

DOI: $10.4000 /$ ideas.6895

ISSN: 1950-5701

\section{Editora}

Institut des Amériques

\section{Refêrencia eletrónica}

Edson Dalmonte e Priscilla Dibai, « A direita radical 'bolsonarista': da aporofobia à defesa da memória de regimes de exceção », IdeAs [Online], 14 | 2019, posto online no dia 01 outubro 2019, consultado o 10 dezembro 2020. URL : http://journals.openedition.org/ideas/6895 ; DOI : https://doi.org/10.4000/ ideas.6895

Este documento foi criado de forma automática no dia 10 dezembro 2020 


\section{A direita radical 'bolsonarista': da aporofobia à defesa da memória de regimes de exceção}

The radical right of Jair Bolsonaro: from aporophobia to the defense of the memory of exception regimes

La droite radicale de Jair Bolsonaro: de l'aporophobie à la défense de la mémoire des régimes d'exception

La derecha radical de Jair Bolsonaro: de la aporofobia a la defensa de la memoria de los regímenes de excepción

Edson Dalmonte e Priscilla Dibai

\section{Introdução}

1 A defesa de modelos restritivos e autoritários de Estado e sociedade por políticos eleitos democraticamente tem chamado a atenção de pesquisadores de todo o mundo, desde o final do século XX. No Brasil, esse tipo de modelo tem ascendido e encontrado ressonância principalmente em discursos e performances de Jair Bolsonaro, que foi deputado federal por 30 anos e eleito presidente da República, em outubro de 2018.

o pressuposto adotado por este artigo é de que há uma versão mais radicalizada de direita, que sustenta determinadas particularidades e rotinas que se alinham com o que a literatura internacional tem conceituado como 'novo radicalismo de direita', cujos líderes participam do sistema de regras democrático, mesmo que suas ideias/propostas imponham contradições aos princípios, valores e crenças da própria democracia representativa (Minkenberg M., 1998).

3 A partir dessa premissa, o trabalho analisa discursos de Jair Bolsonaro em meios de comunicação, de 1986 a 2017, bem como sua atuação política na Câmara Federal, com o objetivo de compreender como esse ator mobiliza e insere os temas do nacionalismo, 
xenofobia, racismo, Estado forte e (anti)democracia no debate público, identificando similaridades e divergências em relação a outros casos internacionais, já mapeados pela literatura.

4 Autores têm indicado que uma nova direita radical ressurgiu no final dos anos 1970, muito relacionada a efeitos desestabilizadores nos pilares da 'família', 'nação' e 'tradição', a partir da política de abertura de mercados e privatizações e inserção da tecnologia na vida cotidiana, que resultou em grandes fluxos migratórios, formação de blocos econômicos transnacionais e intensa modificação nas relações homem $x$ sociedade (Giddens A., 1996; Betz H.-G., 1993). Além disso, a literatura aponta convergências, regularidades e similaridades entre as mais diversas ocorrências, mesmo em países e culturas diferentes (Langenbacher N. e Schellenberg B., 2011; Norris P., 2005; Tostes A., 2009).

5 Grande parte da teoria tem sinalizado não apenas o aumento no número de partidos políticos, mas, principalmente, a efetividade e força com que os radicais de direita vêm disputando espaço, adesão e poder, seja no cenário político-eleitoral seja na Internet ou nas ruas. Schain et al (2002) indicam que a presença e as propostas da direita radical têm se tornado cada vez mais normalizadas, tanto na percepção popular quanto na disposição dos demais partidos em compor com esse espectro, a aumentar as chances nas disputas locais e nacionais.

O conceito de direita radical passa pela discussão de suas características fundadoras, sobre as quais não há consenso. Em 26 definições pesquisadas por Mudde (1996), são mencionados 58 aspectos diferentes, sendo que apenas cinco se repetem em pelo menos metade dos autores: nacionalismo, racismo, xenofobia, Estado forte e antidemocracia. Esse autor, que posteriormente testou essas características em cinco partidos europeus (Mudde C., 2000), serve como referência importante para este trabalho, que replica a ideia no caso brasileiro, não em partidos políticos, pelas especificidades do nosso contexto, mas para pensar a atuação e ascensão de uma das principais lideranças do espectro, no país.

7 No campo da pesquisa, há uma tendência forte em defender mudanças entre o radicalismo de direita recente e o nazifascismo da primeira metade do século XX. Minkenberg (2011), por exemplo, afirma que essa renovação parte do conceito de “ ethnopluralism", que se diferencia do antigo discurso nazifascista baseado na hierarquia da diferença racial. 0 etnopluralismo seria uma estratégia defensiva contra a imigração e a incompatibilidade cultural, a partir da construção de uma filiação nacional, na qual critérios étnicos, culturais ou religiosos são acentuados e condensados em ideias de homogeneidade coletiva, ligados a modelos políticos autoritários (Minkenberg, M. 2011). Ele acredita que a direita radical recente não quer voltar a regimes prédemocráticos, tais como a monarquia ou feudalismo, mas jogar com os antagonismos da democracia para disputar poder e reforçar sua ideia de Estado autoritário, repressivo, fechado e minimamente plural (Minkenberg M., 2000).

8 Conforme indica Mudde (2010), as pautas radicais de direita na Europa têm girado em torno de três temas principais: corrupção, imigração e segurança, de modo que, diferentemente dos políticos tradicionais, suas lideranças não costumam se concentrar em questões socioeconômicas (inflação, desemprego, planos econômicos, acordos internacionais, etc), mas principalmente em temas socioculturais, explorando-os a partir de performances extremadas em meios de comunicação e recorrentes ataques a outgroups (Rydgren J., 2007). 
9 Seguindo esses referenciais teórico-metodológicos, o artigo analisa o caso brasileiro, observando as formas de ocorrência da direita radical no Brasil recente e identificando o que o caso Bolsonaro pode contribuir para a compreensão do fenômeno para além da Europa e dos Estados Unidos.

\section{Metodologia}

O corpus da pesquisa é composto por discursos de Jair Bolsonaro, publicizados na mídia e disseminados para o público em geral. Inclui 26 itens $^{1}$, entre matérias, entrevistas, artigos de opinião e participação em documentário. Para a seleção do material, buscamos incluir a maior variabilidade de datas possível, de maneira a formar um intervalo de tempo representativo, condizente com a longa carreira política do ator. Embora não tenha sido possível evitar certas lacunas, principalmente entre os anos de 1987 a 1996 e 2002 a 2010, acreditamos que esse conjunto de dados possa reconstruir satisfatoriamente as maneiras pelas quais a realidade é narrada por esse ator político (Bauer M. et al, 2004).

11 Também nos preocupamos em selecionar diferentes programas, veículos, apresentadores, horários de veiculação e emissoras/empresas de comunicação. Como parte da análise, realizamos uma ampla investigação sobre a carreira e atuação política do ator analisado, sobretudo no que se refere à maneira como votou no Legislativo ao longo dos 30 anos como deputado (anexo 1), relação com os ex-presidentes da época, principais polêmicas em que se envolveu, pedidos de cassação, projetos de lei apresentados, etc. Levantamento da Fundação Getúlio Vargas (CPDOC-FGV), informações do site da Câmara Federal e arquivos jornalísticos ajudaram na execução dessa etapa.

Todas as entrevistas em vídeo foram transcritas, a fim de evitar imprecisões. Depois de lido, o material foi codificado e analisado de acordo com as categorias que estruturaram a pesquisa: xenofobia, racismo, nacionalismo, Estado forte e antidemocracia, mais categorias extras, nas quais foram registrados outros achados importantes, como posição econômica defendida, posição em relação à ditadura civil-militar e tipos de inimigos construídos. Depois dessa sistematização, foi realizada a análise de cada um dos aspectos, em sintonia com o mapeamento da atuação política do ator no Parlamento.

13 Este trabalho, apesar de adotar rigor nos procedimentos, apresenta algumas limitações. Como já foi mencionado, o corpus possui lacunas temporais, em função de o ator não ter ocupado a mídia de maneira constante e regular ao longo da carreira. Também, por questões de foco, objetivo e limite de espaço, pode deixar de descrever ou se aprofundar nas relações desse ator com outros espectros, grupos, pautas políticas, contextos e problemas sociais e/ou políticas públicas do país. É preciso pontuar ainda que entendemos a direita radical como um espectro em disputa, integrada por diversas correntes e grupos, multifacetada e diversa, não estável nem uníssona, não sendo nosso objetivo reduzi-la a Jair Bolsonaro tampouco a nossa análise. 


\section{Brevíssimo perfil}

14 Jair Messias Bolsonaro nasceu em Campinas (SP), em 1955. Ingressou no Exército em 1977, tendo chegado à patente de capitão. No entanto, com pouco mais de 10 anos de carreira, foi encaminhado à reserva por atos indisciplinares, inclusive pelo plano 'Operação beco sem saída', no qual ameaçava explodir bombas de baixa potência na Academia Militar das Agulhas Negras e em vários quartéis, por reajuste salarial ${ }^{2}$. Em 1988, venceu sua primeira eleição, como vereador do Rio de Janeiro. A partir disso, foi deputado federal por sete mandatos consecutivos, de 1990 até 2017.

Embora tenha protagonizado atos infracionais contra as Forças Armadas, é defensor da memória da ditadura civil-militar de 1964 e tem os militares como seu principal nicho de apoio, pelo menos até 2012, quando supomos que ele tenha ganhado mais visibilidade e representatividade, conquistando simpatia/apoio de outros grupos, sobretudo evangélicos e parte da classe média ressentida com a esquerda/ $/ \mathrm{PT}^{3}$ (Partido dos Trabalhadores).

Ele se declara católico, ainda que tenha protagonizado uma celebração de batismo evangélico no rio Jordão, em Israel, em 2016. Mantém estreita ligação política com a bancada e grupos evangélicos, sobretudo nas pautas morais. Também é muito próximo da 'bancada da bala', que reúne políticos alinhados com a defesa do empoderamento das forças de repressão e liberação do porte de arma; e, nos últimos anos, tem se aproximado dos ruralistas, principalmente na defesa da flexibilização de leis ambientais e na ampliação dos benefícios financeiros a esse segmento.

17 A maioria dos projetos apresentados no Parlamento está relacionada à segurança pública e defesa da categoria militar. Aprovou apenas dois projetos de lei, porém nenhum referente a esses temas, sendo: extensão da isenção do Imposto sobre Produto Industrializado (IPI) para bens de informática e uso da "pílula do câncer" (fosfoetanolamina sintética). Aprovou uma emenda à Constituição, em 2015, referente à impressão do voto após uso da urna eletrônica, questão contestada pela Procuradoria Geral da República e ainda em discussão no Supremo Tribunal Federal ${ }^{4}$.

Ao longo da carreira política, foi alvo de pelo menos 30 pedidos de cassação do mandato ${ }^{5}$, a imensa maioria por quebra de decoro parlamentar. Desses, apenas três chegaram a tramitar no Conselho de Ética, mas foram arquivados em seguida (Dibai P., 2018). Formou em torno de si o clã Bolsonaro, integrado pelos três filhos políticos: Eduardo, que é deputado federal por São Paulo; Flávio, senador pelo Rio de Janeiro; e Carlos, vereador pelo município do Rio de Janeiro.

\section{Análise do caso Jair Bolsonaro}

\section{Concepções de Nacionalismo}

19 Ainda que não seja uma exclusividade da direita radical, o nacionalismo é um aspecto muito importante para a problematização e compreensão desse espectro. A perspectiva nacionalista está relacionada ao surgimento do Estado nacional, como resultado da unificação dos indivíduos de mesma língua, cultura e tradições em um território (Bobbio N. et al, 1998). Assim, a exaltação à nação substituiu a antiga adoração ao rei, com a modificação de que, na monarquia, independentemente da nacionalidade, todos 
eram súditos do monarca, enquanto que no estado nacional, os estrangeiros passaram a significar ameaça (Mosca G. e Bouthoul G., 1987).

$\mathrm{Na}$ análise empírica, percebe-se que o tema do nacionalismo aparece muito vinculado ao militarismo. A temática militar é tão importante na visão de mundo de Bolsonaro que aparece em $78 \%$ dos materiais pesquisados. A defesa da memória/legado da ditadura é, de longe, o tema mais falado. $O$ interessante é que os posicionamentos são todos positivos à ditadura, nunca como crítica, pedido de desculpa ou reflexão dos equívocos. Sempre a postura assumida é a de defesa dos militares ou da memória do regime, seguida de ataque à esquerda e/ou aos guerrilheiros.

21 Em suas narrativas, as Forças Armadas são exaltadas nos planos social, moral e político.

A ditadura de 1964 é construída como aquela que defendeu o Brasil da ameaça comunista iminente, que apenas reagiu à violência dos grupos paramilitares armados, que não foi corrupta e que fez uma ótima gestão econômica.

(Sente saudade na ditadura) Do respeito às autoridades, aos professores, do pleno emprego, da segurança e da seriedade como se tratava a coisa pública. Não há notícia de um só oficial-general, coronel, capitão ou sargento que tenha enriquecido. Essa foi a principal causa de o Brasil ter passado da $49^{\mathrm{a}}$ para a $8^{\mathrm{a}}$ economia mundial. Os militares não eram corruptos. (ÉPOCA, 2011, versão online ${ }^{6}$ ) Que época (ditadura militar) maravilhosa! Você podia ir para a rua com segurança, a tua família era respeitada, policial era policial, tá ok?! O Brasil passou da $49^{\text {a }}$ para $8^{\mathrm{a}}$ economia do mundo. $O$ Médici fez 15 hidrelétricas. (PROGRAMA DO JÔ, 2005ㄱ)

22 A exaltação do militarismo é percebida desde 1986 - quando publicou seu primeiro artigo em meios de comunicação, cobrando salários mais justos para o Exército ${ }^{8}$ - até 2017 - quando afirmou que colocaria militares em metade dos ministérios, caso fosse eleito presidente da República ${ }^{9}$. No entanto, ao longo desse tempo, os temas variaram de reivindicações salariais para defesas cada vez mais contundentes da ditadura e seus atos, inclusive com a prática de negacionismo histórico. No salvaguardo do regime, ele adota linhas de argumento nem sempre retilíneas ou constantes. É o que acontece com a tortura. Por vezes, assume que existiu, reafirmando que havia uma 'guerra' e/ou 'risco de comunização' do país. Em outras, nega prontamente que a prática tenha existido, alegando que a esquerda se vitimiza e 'considera qualquer coisa como tortura'.

Entrevistador: Deputado, deputado, o governo militar torturou ou não?

Bolsonaro: Sim, torturou. Sim. E daí?

Entrevistador: E aí, o senhor defende isso?

Bolsonaro: A tortura é uma arma de guerra. Como eles (guerrilheiros) nos torturaram. (...) Então, guerra é guerra, guerra é guerra, tá certo?! (BRASIL EM DISCUSSÃO, 2012 ${ }^{10}$ )

Entrevistador: Foi a época (na ditadura militar) em que mais se torturou no Brasil. Bolsonaro: Se você for hoje à Papuda (complexo penitenciário no Distrito Federal), vai ver gente sendo torturada, o pessoal se vitimiza.

Entrevistador: Estamos falando de presos políticos.

Bolsonaro: Que presos políticos? Eles estavam no foquismo. Eles queriam fazer o que Fidel Castro fez em 1959, na Sierra Maestra. Esses caras (guerrilheiros) são doentes mentais. (CORREIO BRAZILIENSE, 2015 ${ }^{11}$ ) 
Quadro 1 - Ideias e argumentos em defesa da ditadura militar

\begin{tabular}{|c|c|}
\hline Ideias defendidas & Argumentos relacionados \\
\hline $\begin{array}{l}\text { Não houve ditadura. } \\
\text { Não houve golpe. }\end{array}$ & $\begin{array}{l}\text { * Durante o regime militar, havia liberdade, imprensa livre, } \\
\text { eleições, direito de ir e vir. Que ditadura é essa? } \\
\text { *Foi o Congresso quem destituiu João Goulart. Não houve } \\
\text { golpe. }\end{array}$ \\
\hline $\begin{array}{l}\text { A população pediu que os militares } \\
\text { assumissem o poder. }\end{array}$ & $\begin{array}{l}\text { *A população, as famílias, os religiosos, temiam a } \\
\text { comunização. Eles foram às ruas e pediram intervenção } \\
\text { militar. } \\
\text { * Os militares sempre defendem o país de qualquer ameaça. } \\
\text { O comunismo era um risco. }\end{array}$ \\
\hline $\begin{array}{l}\text { Não houve tortura. } \\
\text { Houve tortura, mas foi necessário. }\end{array}$ & $\begin{array}{l}\text { *Houve tortura, mas era uma situação de guerra. } \\
\text { * Guerra é guerra. Abusos foram necessários. } \\
\text { * Não houve tortura. A esquerda se vitimiza. } \\
\text { *Ditadura matou pouca gente. } \\
\text { * Os excessos cometidos compensaram a liberdade que se } \\
\text { tem hoje. }\end{array}$ \\
\hline $\begin{array}{l}\text { Guerrilheiros queriam implantar o } \\
\text { comunismo no Brasil. } \\
\text { A esquerda nunca lutou por } \\
\text { democracia. }\end{array}$ & $\begin{array}{l}\text { * A esquerda bombardeou, torturou e matou. A política } \\
\text { deles era a execução. } \\
\text { *A esquerda queria comunizar o Brasil. } \\
\text { * Os guerrilheiros são traidores da Pátria e deveriam ter sido } \\
\text { exterminados. }\end{array}$ \\
\hline $\begin{array}{l}\text { Ditadura como 'ótima época': segura, } \\
\text { moral e harmoniosa }\end{array}$ & $\begin{array}{l}\text { *Havia pleno emprego. Passou-se da } 49^{\mathrm{a}} \text { para } 8^{\mathrm{a}} \text { economia. } \\
\text { * Sinto saudade do regime militar. Havia respeito, } \\
\text { autoridade, ordem e segurança. } \\
\text { *Na época dos militares, não havia corrupção. }\end{array}$ \\
\hline
\end{tabular}

Nos primeiros 15 anos como deputado, Bolsonaro se mostrou contrário às medidas neoliberais dos governos Collor e Fernando Henrique Cardoso, sobretudo privatizações, sucateamento das estatais, subserviência ao FMI (Fundo Monetário Internacional), crescimento da dívida externa e entrada massiva de capital estrangeiro no país.

Barbaridade é privatizar, por exemplo, a Vale do Rio Doce como ele (FHC) fez, é privatizar as telecomunicações, é entregar nossas reservas petrolíferas para o capital externo(...) (PROGRAMA DO Jô, 2005)

24 A partir de 2014, começou a adotar uma posição um tanto contraditória sobre a economia, que mescla autoritarismo com neoliberalismo, vontade de controle sobre a iniciativa privada com a diminuição do Estado. Desde esse período, tem se afirmado liberal, defensor da propriedade privada, da meritocracia e assumido discursos próempresários e ruralistas, contra direitos dos trabalhadores (INFOMONEY, 2014 ${ }^{12}$ ). Comentou certa vez que é justo mulheres ganharem menos por engravidarem (ZERO HORA, 2014 ${ }^{13}$ ). Também mudou de opinião sobre as privatizações, defendendo a venda de certas estatais.

(...) sou totalmente a favor da meritocracia, do livre mercado, mas claro que não é tudo, afinal, eu sou a favor de um governo autoritário. o governo não pode perder a mão e deixar tudo no [setor] privado, senão vira palhaçada (....) Têm coisas que não dá para não privatizar. 0 setor de telecomunicações, por exemplo, não tinha como não ter sido feito, mas a privatização da Vale eu fui contra... Petrobrás, eu sou contra. (INFOMONEY, 2014)

Eu sou um liberal, se eu quero empregar você na minha empresa ganhando $\mathrm{R} \$ 2$ mil por mês e a Dona Maria ganhando R\$ 1,5 mil, se a Dona Maria não quiser ganhar isso, que procure outro emprego! 0 patrão sou eu. (ZERO HORA, 2014)

Jair Bolsonaro não costuma assumir discursos idealizados de nação nem do povo brasileiro, embora faça, algumas vezes, generalizações nesse sentido. Também não costuma endossar o discurso nativista que apela para o laço sanguíneo ou para o 
pertencimento territorial. Inclusive, tem se mostrado contrário aos direitos de povos tradicionais, como índios e quilombolas ${ }^{14}$, da mesma forma que vê os nordestinos como um grupo diferenciado, contribuindo para sua estigmatização ao considera-los "refém dos políticos da seca" (BRASIL EM DISCUSSÃO, 2012) ou excessivamente dependentes de benefícios sociais (THE NEW YORK TIMES, 2016 ${ }^{15}$ ).

O Brasil é retratado por Bolsonaro a partir de seus problemas de corrupção, alta criminalidade, maus governantes (de Collor a Dilma Rousseff fez crítica a todos, embora em graus variados) e políticas equivocadas (das privatizações às cotas). Os elementos verdadeiramente motivadores para a reconstrução da nação não viriam de sua realidade material, que deixa a desejar, mas do desejo por um Executivo centralizador e poderoso, intransigente em relação aos valores morais, que exalta a autoridade e a exclusividade da família heterossexual, que governa ao lado das Forças Armadas, sob o alento da religião. A partir dessas bases, que emolduram sua sociedade desejada, tenta construir sua imagem como um político capaz de honrar a Deus e 'salvar' a pátria, forjando-se como decente, corajoso, independente, defensor dos bons costumes, que não deve favores e não teme ninguém, como aquele que não foi comprado pelo PT, que não está citado no Mensalão e nem no escândalo da Petrobras (Petrolão) ${ }^{16}$ (Dibai P., 2018).

\section{Xenofobia}

A xenofobia é um tipo de pensamento/sentimento que considera os estrangeiros como ameaça e/ou risco à unidade, pureza e/ou estabilidade da nação. A postura xenófoba estaria muito vinculada ao autoritarismo e ao nacionalismo, que seriam seus principais sustentáculos (Mudde C., 2000). Pela teoria, essa visão se manifestaria por meio de discursos de radicalização das diferenças culturais, étnicas, religiosas e políticas entre os grupos nativos e não-nativos (Minkenberg M., 2011), de maneira que os não-nativos são vistos como 'impuros', 'despertencentes' e imorais. Como efeitos desse sentimento/ ideia estão apelos a políticas imigratórias mais rígidas, desburocratização dos processos de deportação e maior controle sobre os imigrantes.

Embora a xenofobia não tenha se mostrado uma pauta recorrente ou central nos discursos de Jair Bolsonaro - como a literatura tem indicado nos casos europeus -, suas posições a respeito do tema merecem descrição e problematização. A partir da análise dos dados, identificou-se que, nesse ator, os estrangeiros são vistos de forma claramente desigual, a depender do status socioeconômico e da cultura do país de origem. Enquanto os europeus e estadunidenses são geralmente bem aceitos (ou não criticados), mulçumanos, africanos e latinos tendem a ser estigmatizados, figurando como ameaças, seja pelos aspectos cultural, religioso, econômico ou ideológico.

Em relação aos europeus ou estadunidenses, Bolsonaro diz que eles vêm suprir mão de obra especializada que no Brasil não tem (ÉPOCA, 2011), posicionando-os como qualificados profissionalmente. Já senegaleses, iranianos, bolivianos, sírios e haitianos são classificados como "escória do mundo" (JORNAL OPÇão, 2015 ${ }^{17}$ ), representados como 'mais um problema' para o país.

(...) senegaleses, haitianos, iranianos, bolivianos e tudo que é escória do mundo, né?! E agora estão chegando também os sírios aqui. A escória do mundo está chegando aqui no nosso Brasil, como se a gente já não tivesse problemas demais para resolver. Esse é um grande problema que nós podemos ter. (JORNAL OPÇÃO, 2015) 
haitianos figuram como um dos alvos principais e são entendidos em associação direta com a miséria e o caos sociopolítico de seu país de origem. São retratados como aqueles que oferecem riscos sanitários e podem trazer novas doenças ao Brasil.

Agora ele (o haitiano) vem pra cá e não toma uma vacina... vai tudo para São Paulo. Tem uns problemas de saúde aparecendo aqui (no Brasil), coisa nova. Não é discriminar o haitiano. (NYT, 2016)

O Haiti é citado como o lugar que 'não tem nada', sujo, miserável, com 'mulheres se oferecendo para a prostituição ou para serem empregadas domésticas no Canadá', com 'lodo no lugar de rios' (NYT, 2016).

Quando uma menina começa a se aparecer na sala de aula, depois de uma certa idade, ela vai ser empregada doméstica no Canadá, que fala a língua dela. Isso é o Haiti. Hoje em dia, não tem nada lá. (...) Carvão lá, o galho de carvão lá, é da grossura do dedo mindinho. Lá por exemplo não tem rio, é lodo, tá ok? Eu vi mulher lá se oferecendo lá, o sexo, sem higiene nenhuma (...) (NYT, 2016)

Os mulçumanos, por sua vez, tendem a ser considerados como essencialmente perigosos, diretamente associados ao terrorismo e ao radicalismo político, que oferecem riscos por querer impor sua cultura.

Agora gente do Hamas não dá, do Estado Islâmico não dá. Tá ok? (...) E outra, que venha pra cá para querer impor a sua cultura, também não. (NYT, 2016).

Assim, percebe-se que Bolsonaro tende a dividir os imigrantes entre superiores qualificados, que vêm para o Brasil para suprir aquilo que falta, que contribui com o país - e os inferiores - pobres, cuja vinda para o Brasil traz algum tipo de desordem, que afeta o país negativamente. Esse tipo de raciocínio/sentimento passa pelo que Cortina (2017) chama de aporofobia. Ela argumenta que a aversão não existe a todo e qualquer estrangeiro, mas apenas a uma parte deles, aqueles que não têm posses, os pobres, mal vistos e malquistos, desprezíveis na hegemonia capitalista, de modo que a intolerância à pobreza seria o sustentáculo do desprezo a certos imigrantes.

\section{Racismo}

Autores como Minkenberg (2011) e Wieviorka (1998) têm indicado que o discurso racista não se fundamentaria mais na hierarquização da raça, como ocorrera no nazismo, mas na inferiorização e/ou negativização de certas culturas. De acordo com essa perspectiva, o racismo típico da segunda metade do século XX se manifestaria como aversão e/ou medo do que a diferença cultural de certos grupos traria e/ou imporia para as identidades do grupo dominante e/ou à homogeneidade nacional. Apesar de ser uma interpretação de grande ressonância, este trabalho não acredita que houve superação completa das práticas de hierarquização racial ou do preconceito de cor, ainda que reconheça ter havido, em muitos países, inclusive no Brasil, um aumento da pressão social contra o discurso abertamente racista.

No corpus analisado, a temática racial aparece em 25 trechos, em oito entrevistas. As falas tratam de três questões principais: 1 ) posição contrária às cotas para negros (44\% das citações); 2) versão sobre o incidente com Preta Gil, em 2011, que o processou por racismo, após ele declarar na TV que os filhos não se casariam com uma negra, porque foram bem educados $(32 \%)$; 3 ) posição contrária à demarcação de terras e benefícios para povos indígenas e quilombolas (16\%). 

justificativa na retórica pacificada de que 'todos são iguais perante a lei', de modo que os negros não merecem 'tratamento' ou políticas diferenciadas apenas por serem negros, forjando a igualdade como algo natural e não social e política.

o que é que o negro tem de inferior a mim? (...) nós temos de partir do princípio de que todos nós somos iguais perante a lei. Não podemos criar privilégios (...) (PROGRAMA DO RATINHO, 2014 ${ }^{18}$ )

A sustentação do argumento exclusivamente na ideia de "iguais perante a lei" é a estratégia utilizada para modalizar a cota como privilégio ou injustiça, disputando a reversão de seu sentido e fomentando a polarização, à medida que coloca em condição de rival negros e brancos pobres. Assim, ele constrói o discurso alarmista de que o sistema de cotas é divisionista e reflete a "política do ódio" da esquerda, priorizando injustamente o 'afrodescendente' e prejudicando os demais.

(...) entre um filho afrodescendente e um filho da Paraíba, porque um filho afrodescendente tira uma nota menor e vai pra faculdade e o do paraibano, que é sofrido também, que ele e o pai virou (viraram) laje pra fazer prédio aqui, não vai pra faculdade, e o do afrodescendente vai? É a política do ódio, da luta de classes. Lênin explica isso. Branco contra negro, homo contra hétero, homem contra mulher, é comum no Brasil. (NYT, 2016)

Também desqualifica a capacidade de formação/profissionalização dessa política, ao atribuir significado pejorativo ao termo cotista.

Eu não entraria em um avião pilotado por um cotista nem aceitaria ser operado por um médico cotista. (CQC, 2011 $\left.{ }^{19}\right)$

O que chama a atenção é que seus discursos ignoram ou distorcem toda a discussão social, política e histórica que guiaram ou justificaram a implementação do sistema de cotas raciais no Brasil, inclusive seu principal objetivo, o de aumentar o acesso de negros e negras ao ensino superior e serviço públicos. Está evidente nas falas de Bolsonaro a ausência de qualquer problematização em relação à questão racial no país. Prova disso é que, quando perguntado sobre o que acha da mistura de raças no Brasil, responde:

Sem problemas. Aqui é um paraíso. Por isso é que eu sou contra as cotas. (NYT, 2016)

Assim, fica perceptível em seus enunciados a repetição de uma ideia que vem estruturando o pensamento social brasileiro por séculos: a de que as diferentes raças convivem harmônica e pacificamente no país, naturalizando dominações e opressões. Como lembra Almeida (2017), boa parte do pensamento social sobre o Brasil ancora-se na ideia de cordialidade, mesmo com toda a sua violência, ainda que não explícita.

Diferentemente dos achados de Pierucci (1990), quando ele detectou que os radicais de direita tendiam a demarcar diretamente que o "negro é diferente do branco", Bolsonaro segue a estratégia retórica de igualá-los, desarmando a força e a celebração das diferenças que Pierucci anuncia e considera estrutural no pensamento racista brasileiro no fim do século XX. Isso leva a pensar que as retóricas em torno do racismo são variantes, admitindo contornos múltiplos e argumentos multifacetados. No entanto, mesmo com essa divergência, no fim, os significados parecem caminhar para os mesmos objetivos: construir distâncias entre as raças para evitar ampliação de direitos e poder, com o incremento de que Bolsonaro ancora e consuma seu incômodo com as conquistas negras na ideia de privilégio e/ou injustiça e não na demarcação da diferença das raças. 
Em relação ao caso Preta Gil, ele alegou diversas vezes que não é racista e que foi vítima de má fé por parte do programa, que o induziu ao erro. No entanto, no Brasil é raríssimo alguém se declarar publicamente racista. 0 racismo normalmente aparece de forma velada e indireta, muitas vezes complexa, em signos de inferiorização/ ridicularização dos modos de ser/viver desse grupo ou na limitação de seu acesso a políticas, direitos e ascensão, embora nem sempre proclamados.

Bolsonaro também é contrário à demarcação de terras para os povos indígenas. Em seus discursos, quer passar a ideia de que as demarcações inutilizam áreas enormes, que poderiam ser agricultáveis ou profissionalmente cultivadas, gerando riquezas para o país. Julga como absurdo o fato de a Amazônia, a área mais rica do mundo, estar sob o controle dos índios. Em suas falas, o elemento de disputa é a terra. Sua preocupação central ou motivo de interesse é com o valor material da terra e não, necessariamente, com a discussão social, política e histórica em torno dos grupos que a ocupam. Pela força que a terra representa na perspectiva capitalista, ele vê as comunidades primitivas como aquelas que impedem o solo de gerar/virar riqueza e lucros. A demarcação é vista como uma política antinacional, antidesenvolvimentista e improdutiva.

4 Percebe-se, assim, também no caso das demarcações, a intenção de afastar indígenas e quilombolas de políticas sociais e direitos, principalmente relacionados à terra. Contra os índios, são mobilizados os significados de desproporcionalidade - 'são poucos para muita terra' - e improdutividade - 'terras excelentes que foram demarcadas e estão ociosas'. Em relação aos quilombolas, o referente 'improdutividade' ganha força, à medida que a imagem dessa população é vinculada à preguiça e ao ócio absoluto. Assim, diferentemente da estratégia que utiliza na retórica das cotas, ao igualar negros e brancos, com índios e quilombolas ele evidencia as diferenças, criticando seus hábitos e seus modos de ser/viver.

Reservas indígenas, um crime o que acontece no nosso país, essa demarcação de terra indígena. (BRASIL EM DISCUSSÃO, 2012)

(...) uma área do tamanho do Rio de Janeiro, enorme estado, multiplica por dois: reserva ianomâmi, nove mil índios. (NYT, 2016)

Com tudo isso, no caso analisado, o signo do privilégio tem um papel importantíssimo como o ponto onde é materializada, apoiada e disfarçada a intenção de construir distâncias entre brancos e não-brancos (índios, negros e quilombolas). A ideia de privilégio é sustentada tanto pela perspectiva da injustiça (contra os demais pobres, contra as demais minorias) quanto pela meritocracia ('o que eles fizeram para merecer isso?), ideia muito forte e recorrente nas ideologias de direita. Uma vez construída como privilégio, as políticas compensatórias/emancipatórias se transfiguram em imoralidade, o que justifica seu combate e oposição. 0 esforço discursivo de Bolsonaro é, a partir disso, inverter a lógica dessas ações, reforçando ao mesmo tempo sua visão econômica de que o Estado deve evitar benefícios e políticas sociais.

Há um duplo e imbricado aspecto que nos permite sugerir dois incômodos principais no tema do racismo: à questão racial propriamente dita, que tem como base o naturalismo hierarquizante de que o negro/quilombola não está no mesmo nível intelectual-moral de um branco; e ao incômodo com a ascensão social, cultural, política e econômica dos negros em uma sociedade historicamente escravista e desigual, que tem se reproduzido a partir de relações duradouras de dominação e opressão sobre essa população. 


\section{Estado repressor e punitivo}

47 A partir da análise empírica, identificamos que a defesa de um Estado penal, repressor e punitivo tem destaque no conteúdo discursivo de Jair Bolsonaro, figurando entre seus temas mais abordados e uma de suas bases ideológicas principais. A pena de morte, a prisão perpétua e endurecimento das leis são justificados por meio de discursos como: 'a árvore que não der frutos deve ser cortada e lançada ao fogo' ${ }^{20}$, 'quem morre não volta para matar mais ninguém' ${ }^{21}$, 'os bandidos são, na maioria dos casos, irrecuperáveis'22 e 'essas penas diminuiriam a população carcerária’²3.

Bolsonaro tem defendido sistematicamente a redução da maioridade penal, com frequentes e contundentes ataques a menores infratores, vistos como 'vagabundos' e 'marginais', que precisam ser punidos, contidos e encarcerados urgentemente. Suas posições contra esse grupo são duradouras, de 1993, quando vota favoravelmente na PEC 171-1993 (não aprovada) até 2017.

Quando se fala em menor vagabundo, você tem que ter uma política para aprisionar esses caras, buscar a redução da maioridade penal e não defender esses marginais, como se fossem excluídos da sociedade. Não são excluídos, são vagabundos. (PROGRAMA DO RATINHO, 2014)

Também é favorável à castração química para estupradores e trabalho forçado para presidiários. Afirma-se contrário aos direitos humanos, sob os argumentos de que essa 'política favorece os bandidos' e/ou 'bandidos não deveriam ter direitos humanos'; 'é preciso rigidez para lidar com os criminosos'; e 'certas informações, o bandido tem que dizer ${ }^{24}$. A ideia de que os direitos humanos significam mordomia para presos não é nova no Brasil entre os apoiadores da direita radical, tendo sido identificada por Pierucci (1987), desde o fim dos anos 1980. No entanto, para além desse espectro, Caldeira (2000) também encontrou, em sua tese, forte resistência ao cumprimento ou respeito aos direitos humanos em diversos grupos sociais, alertando que nem mesmo após a redemocratização, o país tem mostrado avanços no fortalecimento dessa política/princípio.

Bolsonaro chega a fazer defesas explícitas da tortura, principalmente nas duas primeiras décadas de sua carreira política (até 2007). Depois, passa a evitar o termo, adotando expressões indiretas como "tratamento/método enérgico". Em uma entrevista, explica que "método enérgico" é controlar a alimentação, bebida e cela do preso, a forçá-lo a falar.

Um traficante que age nas ruas contra nossos filhos tem que ser colocado no paude-arara imediatamente. Não tem direitos humanos nesse caso. É pau-de-arara, porrada. Para sequestrador, a mesma coisa. $O$ objetivo é fazer o cara abrir a boca. 0 cara tem que ser arrebentado para abrir o bico (ISTOÉ GENTE, 2000²5).

Pegaram um irmão de um deputado federal em São Paulo, com 500 quilos de cocaína em um caminhão. (...) Esse cara tem que falar. 'Amigo, fica aqui, chegou a hora do almoço, tá com fome? Eu quero saber de onde veio essa droga?' Não tem almoço, isso é tortura? Quantas famílias esses caras levam à miséria? Que passam fome por causa das drogas? Crianças são executadas que servem como aviãozinho e depois não repassam o dinheiro e são executadas. Torturados estamos sendo nós, pessoas de bem. Deixa o cara sem almoço ali, não tem janta, dá só um biscoitinho pra ele. Não precisa torturar o cara, ele vai contar. (NYT, 2016)

51 Em suas falas, Bolsonaro não faz referência ao sujeito torturador, que fica implícito, embora facilmente identificável, mas explicita as figuras a serem torturadas: sequestradores e traficantes de drogas, por exemplo. Essa ênfase no torturado reforça 
tanto sua vontade/intenção de demarcar grupos indesejados, quanto de justificar a tortura como um instrumento recursivo do Estado, útil para 'limpar' a sociedade.

O tema do porte de arma de fogo gira em torno, principalmente, do argumento: 'o bandido está armado, enquanto o governo desarmou o cidadão de bem' (em referência ao Estatuto do Desarmamento, do qual Bolsonaro é totalmente contrário). O porte de arma é defendido não apenas como um direito, mas como uma necessidade, visto que o 'cidadão de bem' precisa proteger a si e a sua família da violência.

Nesse sentido, os policiais são isentados de qualquer responsabilidade sobre o problema da violência no país. Nos discursos de Bolsonaro, esse grupo aparece como heróis nacionais, como aqueles que enfrentam a guerra nas ruas, que mesmo expostos à criminalidade, não são valorizados pelo Estado e sociedade. Os policiais são retratados como os defensores dos 'cidadãos de bem' e integram, na sua visão polarizada, o lado honrado e bom da sociedade, contra o mundo cruel do crime e da marginalidade, sendo quaisquer excessos e abusos cometidos por eles resultado da guerra nas ruas.

Quadro 2 - Resultados qualitativos Estado forte

\begin{tabular}{|c|c|c|c|c|}
\hline Temas & LEGAL/PENAL & $\begin{array}{l}\text { ANTI-DIREITOS } \\
\text { HUMANOS }\end{array}$ & $\begin{array}{c}\text { PORTE DE } \\
\text { ARMA }\end{array}$ & $\begin{array}{c}\text { DEFESA } \\
\text { POLICIAL }\end{array}$ \\
\hline \multirow{4}{*}{$\begin{array}{l}\text { Posições } \\
\text { ideológicas } \\
\text { principais }\end{array}$} & $\begin{array}{l}\text { Menor infrator tido } \\
\text { como criminoso. } \\
\text { Menor infrator não } \\
\text { como um problema } \\
\text { social, mas penal }\end{array}$ & $\begin{array}{l}\text { Crença nos Direitos } \\
\text { Humanos como } \\
\text { direito dos bandidos }\end{array}$ & $\begin{array}{l}\text { Crença de que o } \\
\text { porte de arma traz } \\
\text { segurança e/ou } \\
\text { protege o cidadão }\end{array}$ & $\begin{array}{l}\text { Heroicização da } \\
\text { polícia, como } \\
\text { aquela que arrisca a } \\
\text { vida em defesa da } \\
\text { sociedade }\end{array}$ \\
\hline & $\begin{array}{l}\text { Defesa de penas } \\
\text { mais duras, como } \\
\text { prisão perpétua e } \\
\text { pena de morte }\end{array}$ & $\begin{array}{c}\text { Defesa/naturalização } \\
\text { da tortura, } \\
\text { modalizada como } \\
\text { 'necessidade' }\end{array}$ & $\begin{array}{c}\text { Críticas ao } \\
\text { Estatuto do } \\
\text { desarmamento }\end{array}$ & $\begin{array}{l}\text { Narrativa de que há } \\
\text { uma guerra nas ruas } \\
\text { para empoderar } \\
\text { policiais }\end{array}$ \\
\hline & $\begin{array}{l}\text { Crítica às leis } \\
\text { brasileiras, que } \\
\text { seriam brandas } \\
\text { demais }\end{array}$ & $\begin{array}{c}\text { Descrença na } \\
\text { reintegração de } \\
\text { bandidos. Presídio } \\
\text { deve ser um lugar } \\
\text { horrível, pois é onde } \\
\text { se 'paga pecados' }\end{array}$ & $\begin{array}{l}\text { Crença de que a } \\
\text { arma de fogo } \\
\text { empodera o } \\
\text { cidadão e o lado } \\
\text { bom da sociedade }\end{array}$ & $\begin{array}{l}\text { Narrativa de que a } \\
\text { sociedade está } \\
\text { refém dos bandidos }\end{array}$ \\
\hline & $\begin{array}{l}\text { Pavor à impunidade } \\
\text { é convertido em } \\
\text { ódio ao bandido }\end{array}$ & $\begin{array}{c}\text { Vontade de } \\
\text { revanche/vingança } \\
\text { contra bandidos }\end{array}$ & & $\begin{array}{c}\text { Exploração do } \\
\text { medo para } \\
\text { fortalecer as forças } \\
\text { de repressão }\end{array}$ \\
\hline
\end{tabular}

Já o criminoso é visto como alguém desprovido de origem, classe social, história pessoal e contextos, recortado apenas no ato de seu crime e carimbado como degenerado moral permanente, a quem chama, muitas vezes, de 'vagabundo', 'marginal' e 'canalha' ${ }^{26}$. Com isso, são construídas representações generalizantes tanto da polícia quanto dos bandidos, ambos vistos como blocos uniformes, a partir de quadros morais opostos. Esse tipo de leitura impede a compreensão dos grupos em suas variadas dimensões, assimetrias e contradições. Além disso, contribui para um imaginário social absurdamente desigual, que demoniza um grupo e superempodera o outro, a partir da exacerbação da violência de uns - dos criminosos - e da naturalização da violência de outros - dos policiais.

Dessa maneira, a violência urbana é explorada como pauta, ao mesmo tempo em que a discussão sobre suas causas e circunstâncias é esvaziada, e sua consequência supervalorizada. É exatamente no efeito que está a ênfase da narrativa: no dano provocado, no medo instaurado. É aí que é lançada a força de seu apelo: na reafirmação 
do risco iminente, na possibilidade de ser ferido, de ver "nossos filhos" mortos, de "nossas esposas" serem estupradas, "nossa casa" violada, "nossa dignidade" roubada. Como aponta Pierucci, os atores da direita radical tendem a recorrer à estratégia da chamada 'defesa de si', de maneira que suas opiniões e ações, mesmo alarmistas, potencialmente violentas e até preconceituosas, pareçam justificáveis pelo desejo de proteger suas vidas, casas, bens, família e os valores cristãos (Pierucci F., 1987).

No caso da violência urbana, os desejos de punição e aversão operam para transformar os bandidos, no que Butler (2017) chamaria de sujeitos "destrutíveis" e "não passíveis de luto", podendo suas vidas serem perdidas ou sacrificadas, uma vez que são modalizados como ameaças à vida e não como grupos sociais vivos. Reconvocando Cortina (2017), que já sinalizou que grupos não hegemônicos tendem a estar mais suscetíveis ao rechaço e as fobias sociais, pode-se sugerir que a defesa do Estado penal no Brasil, tendo em vista que a maioria dos criminosos são oriundos das classes baixas, também acaba corroborando o processo de criminalização da miséria (SINGER, 1998).

\section{Antidemocracia}

57 Embora seja um conceito complexo, a antidemocracia, para os fins dessa análise, foi compreendida como: a) resistência/oposição ao sistema democrático formal (posição contrária ao voto, instituições democráticas, partidos políticos e Estado laico); e b) resistência/oposição aos valores e princípios democráticos (a exemplo da tolerância, pluralidade, diversidade, diálogo e respeito aos direitos humanos).

A partir dos dados, identifica-se que, embora não haja opiniões contrárias ao sufrágio universal, Jair Bolsonaro é muito favorável a regimes autoritários, defendendo a memória e os feitos da ditadura civil-militar de 1964, a qual avalia como "melhor" do que a democracia ${ }^{27}$. 0 termo 'democracia' aparece muito relacionado à crítica ao comunismo e ao PT, a partir da ideia central de que a esquerda não luta(va) pela democracia.

Pergunta: Qual a opinião do senhor sobre a democracia?

Bolsonaro: Vivemos um período de pleno emprego, segurança, liberdade e respeito entre 1964 e 1985. Se houver uma pesquisa entre pessoas com idade superior a 60 anos, tenho certeza de que a quase totalidade concordará com essa afirmação. Hoje, temos medo de ir à escola, pois corremos o risco de sermos assaltados ou assassinados, mesmo durante o dia. Nossa democracia é governada por líderes que idolatram democratas como Fidel Castro, Hugo Chávez, Ahmadinejad e Khadafi. (ÉPOCA, 2011)

$\mathrm{O}$ ator analisado tem criticado a utilidade/papel do Parlamento brasileiro com certa recorrência, ao longo de sua carreira. Discursos com esse teor são identificados em 1997, 1999, 2005, 2012, 2015 e 2016. No entanto, a retórica variou. Na década de 1990, chegou a pedir o fechamento do Congresso e sugeriu transformar o Parlamento em uma delegacia ${ }^{28}$. A partir dos anos 2000 , evita falas tão incisivas, porém continua a representar o Legislativo como um espaço de poder ineficiente, improdutivo e prejudicial ao país, a partir das ideias de que 'o Congresso é totalmente subserviente ao Executivo' (com os parlamentares 'vendendo' votos) e de que 'a Câmara Federal não tem autonomia nem vida própria' e não vota os próprios projetos.

Hoje em dia, eu acho que o Poder Público, quase de maneira geral, está aí para acharcar, para assaltar, para roubar o povo. E digo mais, eu acho que o nosso Parlamento, em Brasília, só existe para dizer que existe democracia, mas absolutamente nada. (CÂMERA ABERTA, 1997) 
Eu estou no sexto mandato e costumo dizer que quando a casa tá (está) cheia, é porque o Executivo assim quis e é para votar algo que é salgado para sociedade. Como novos impostos, como foi aquela taxação de inativos no passado (...) (AGORA É TARDE, 2012)

60 Também afrontou discursivamente o Poder Executivo, defendendo o fuzilamento de Fernando Henrique Cardoso $^{29}$ (enquanto era presidente) e o assassinato de Dilma Rousseff (também enquanto presidente).

Acho que o fuzilamento é uma coisa até honrosa para certas pessoas. (...). Não é difícil matar o presidente. Só tem que ter coragem. O esquema de segurança dele (de Fernando Henrique) é falho. Por exemplo, tenho uma casa no litoral em Mambucabinha, próxima do local onde ele passeia quando vai a Angra dos Reis. Sou primeiro lugar no curso de mergulho do Corpo de Bombeiros do Rio de Janeiro. Bastava planejar. E as chances de sucesso de se cumprir a missão são grandes. Não é difícil eliminar uma autoridade no País. Isso até serve para alertar o presidente. (ÉPOCA, 2011)

Pergunta: Deveriam tê-la (a presidente Dilma Rousseff) matado?

Resposta: Sim, é a minha opinião. Todos esses traidores da pátria deveriam ter recebido pena de morte. Essa é a minha opinião. Espero que nenhum imbecil, ao ler esta entrevista, diga que sou antidemocrático. (PLAYBOY, 2011)

Em relação ao sistema partidário, manifesta pouca confiança e/ou vinculação ideológica com os partidos políticos os quais foi filiado. Seus discursos indicam que ele manteve com essas agremiações apenas uma relação de filiação por exigência das regras democráticas. Como prova disso, diz repetidas vezes que não vota com seu partido e que, mesmo que o partido seja da base governista, ele não apoia o governo.

Sobre os princípios e valores, sacudiu a incontestabilidade do Estado laico, afirmando que a maioria da população brasileira é cristã e que o Estado também deveria ser.

o Estado é laico, mas seu povo não. Somente católicos e evangélicos somam mais de $90 \%$ de brasileiros. A religião é fator de união dos povos e não pode ser desassociada da família, dos bons costumes e da moralidade. (ÉPOCA, 2011)

Também assume narrativas contrárias aos direitos humanos, questionando sua eficácia e aplicabilidade; admite a tortura como um mecanismo útil no enfrentamento da violência urbana; demonstra intolerância ao pluralismo e aversão à diversidade, a partir de posturas de ataque a LGBTQ+, feministas, esquerdistas, professores, cientistas, quilombolas, etc.

Sua visão da democracia não dá conta das contingências sociais e políticas existentes. É moldada, sobretudo, como um procedimento essencialmente eleitoral, no qual os cidadãos meramente escolhem seus representantes por meio do voto. Ele oculta o antagonismo social, os conflitos de interesse, não faz menção às acentuadas desigualdades do país, à concentração de renda e não fala em participação popular. Detectamos o paradoxo de que seu direito à livre opinião se reverte contra princípios da própria democracia, à medida que, em algumas falas, a tolerância e o respeito às diversidades, pluralidades e pessoas são levadas ao limite. Prova disso são as várias acusações de quebra de decoro parlamentar, que levaram a dezenas de pedidos de cassação contra ele, bem como processos no STF e inúmeras polêmicas ao longo da carreira política.

Com tudo isso, a visão de mundo de Bolsonaro tende a afrontar a tolerância, a constranger a laicidade do Estado, a limitar o pluralismo e a diversidade, principalmente pela tendência de não reconhecer a condição paritária ideal que os sujeitos sociais devem ter nos regimes democráticos, não desejando ou não lidando 
satisfatoriamente com a heterogeneidade de interesses, de identidades, bem como com os próprios conflitos da multiplicidade democrática.

\section{CONCLUSÃO} quer substituir o Estado social pelo Estado penal, com menos benefícios sociais, menos seguridade para o trabalhador, menos políticas de reparação sócio-históricas, e, por outro lado, leis mais rígidas, prisões mais seguras, penas mais duras, formas de ordem e controle social mais abrangentes, com absoluta autonomia às forças de segurança.

71 Concluímos que os discursos refletem um ultraconservadorismo punitivista, princípios militaristas fortes, antiesquerdismo e uma suposta inclinação para o liberalismo econômico. Como parte de sua estratégia político-eleitoral, ele explora os assuntos, extrapolando a cautela que a política costuma impor e imprimindo sua marca naquilo que nenhum outro político diria. Faz isso com a violência urbana, quando externaliza profundos desejos de vingança contra bandidos e naturaliza a violência policial; faz isso com a democracia, quando exalta, em comício, o Estado cristão, pede o fuzilamento de um presidente da República eleito ou constrange uma presidenta que foi torturada quando presa política, saudando, em pleno Congresso, em frente às televisões, um 
militar da repressão ${ }^{31}$; faz isso em relação à memória do país, negando ter havido tortura e exaltando um regime que seviciou e matou centenas de opositores políticos.

Com tudo isso, este artigo chama a atenção para os enunciados de viés autoritário e a performance antipluralista que Jair Bolsonaro tem colocado em circulação, bem como sua estratégia discursiva de ressaltar a desordem e o caos social, como forma de justificar medidas drásticas, soluções superficiais, purismos salvadores e simpatias pela violência. Desnaturalizar essas posturas são fundamentais para compreender e aperfeiçoar a democracia brasileira, bem como para compreender o fenômeno do radicalismo de direita, que ascende em boa parte do mundo.

\section{BIBLIOGRAFIA}

Almeida, Ronaldo, 2017. A onda quebrada: evangélicos e conservadorismo. São Paulo: Cadernos Pagu, n. 50.

Bauer, Martin; Gaskell, Gerorge; Allum, Nicholas, 2004. Qualidade, quantidade e interesses do conhecimento: evitando confusões. In: Bauer, Martin; Gaskell, Gerorge (Orgs.). Pesquisa qualitativa com texto, imagem e som: um manual prático. Rio de Janeiro: Vozes (17-36)

Betz, Hans-George, 1993. The New Politics of Resentment: Radical Right-Wing Populist Parties in Western Europe. Comparative Politics, vol. 25, n. 4, (p. 413-427).

Bobbio, Norberto (et al), 1998. Dicionário de Política. Brasília: Editora UNB, $11^{\text {a }}$ ed.

Butler, Judith, 2017. Quadros de guerra: quando a vida é passível de luto? São Paulo: Civilização Brasileira.

Caldeira, Teresa, 2000. Cidade de muros: crime, segregação e cidadania em São Paulo. São Paulo: Edusp.

Colombo, Eduardo (et al)., 2016. Políticas do medo. São Paulo: Intermezzo.

Cortina, Adela, 2017. Aporofobia, el rechazo al pobre: un desafío para la democracia. Barcelona: Paidós.

Dibai, Priscilla, 2018. A direita radical no Brasil pós-redemocratização: o caso de Jair Bolsonaro. Dissertação (mestrado) - Departamento de Ciências Sociais, UFBA.

Giddens, Anthony, 1996. Para além da esquerda e da direita: o futuro da política radical. São Paulo: Editora da Unesp.

Langenbacher, Nora e Schellenberg, Britta, 2011. Introduction: An anthology about the manifestations and development of the radical right in Europe. In (eds). Is Europe on the "right" path? Right-wing extremism and right-wing populism in Europe. Bonn: Bonner Universitats-Buchdruckerei.

Mosca, Gaetano e Bouthoul, Gaston, 1987. História das doutrinas políticas: desde a antiguidade. Brasília: Zahar Editores, $6^{\mathrm{a}} \mathrm{ed}$. 
Minkenberg, Michael, 1998. The Radical Right in Postsocialist Central and Eastern Europe: Comparative Observations and Interpretations. East European Politics and Societies, v. 16, n. 2 (335-362).

Minkenberg, Michael, 2000. The Renewal of the Radical Right: Between Modernity and Antimodernity. Government and Opposition, v. 35, n. 2 (170-188).

Minkenberg, Michael, 2011. The radical right in Europe today: Trends and patterns in East and West. In Langenbacher, Nora e Schellenberg, Britta (eds). Is Europe on the "right" path? Rightwing extremism and right-wing populism in Europe. Bonn: Bonner Universitats-Buchdruckerei.

Mudde, Cas, 1996. The war of words defining the extreme right party family. West European Politics, v. 19, n. 2 (225-248)

Minkenberg, Michael, 2000. The ideology of the extreme right. Manchester: Manchester University Press.

Minkenberg, Michael, 2011. Populist Radical Right Parties in Europe. New York: Cambridge University Press

Norris, Pippa, 2005. A tese da "nova clivagem" e a base social do apoio à direita radical. Opinião Pública, Campinas, v. 11, n 1 (p.1-32)

Pierucci, Flávio, 1987. As bases da nova direita. São Paulo: Revista Novos Estudos Cebrap, nº 19, dez, p 26-45.

Minkenberg, Michael. 1990. Ciladas da diferença. São Paulo: Revista Tempo Social, v. 2, n. 2, p. 7-37. Disponível em http://www.scielo.br/pdf/ts/v2n2/0103-2070-ts-02-02-0007.pdf

Rydgren, Jens, 2007. The Sociology of the Radical Right. Annual Review of Sociology, v. 33, ago 2007 (241-262).

Schain, Martin et al (coord), 2002. Shadows over Europe: The Development and Impact of the Extreme Right in Western Europe. New York: Palgrave MacMillan.

Singer, Helena, 1998. Direitos humanos e volúpia punitiva. São Paulo: Revista USP, n. 37, marçomaio, p. 10-19.

Tostes, Ana Paula, 2009. Razões da Intolerância na Europa Integrada. Dados: Revista de Ciências Sociais, v. 52, n. 2, (335 a 376).

Wieviorka, Michel, 1998. El Racismo: una introducción. Barcelona: Gedisa.

\section{ANEXOS}

Histórico de algumas votações

1990: Sim ao impeachment de Fernando Collor de Mello

1993: Sim à redução da maioridade penal para 16 anos (PEC 171-1993)

1994: Ausente à sessão que rejeitou o fim do voto obrigatório; Sim à criação do IPMF e do Fundo Social de Emergência (FSE), fontes de financiamento para o plano Real 1995: Não à abertura da navegação de cabotagem às embarcações estrangeiras; Não à abolição do monopólio estatal nas telecomunicações e Não à abolição do monopólio estatal na exploração do petróleo (CPDOC-FGV). 
1996: Não à Contribuição Provisória sobre Movimentação Financeira (CPMF); seu projeto pela revogação do Parque Indígena Yanomami foi rejeitado pela Câmara de Deputados

1997: Não à emenda da reeleição para prefeitos, governadores e presidente da República; Não à emenda de reforma administrativa de FHC

2000: Não à criação do Fundo de Combate à Pobreza (foi o único voto contrário)

2001: Sim ao fim de votações secretas nas casas legislativas

2002: Não à prorrogação da CPMF

2004: Sim à chamada lei de Biossegurança, que regulamenta o plantio e a comercialização de produtos transgênicos

2005: Não à proibição da venda de armas (referendo)

Não à PEC que proibia o nepotismo na administração pública

2006: Não à política de cotas e Não à volta da CPMF

2011: Não à privatização dos hospitais universitários

Propôs moção de louvor ao presidente dos Estados Unidos, Barack Obama, pela ação militar que matou o líder da organização Al-Qaeda, Osama Bin Laden.

2012: Não ao projeto de distribuição dos royalties de petróleo do pré-sal entre todos os estados brasileiros; Sim ao novo Código Florestal (mais flexível e permissivo à exploração florestal); ausente à votação da PEC do Trabalho Escravo; propôs moção de louvor ao presidente indonésio pela condenação à morte do brasileiro Marco Archer Cardoso Moreira, preso por tráfico internacional de drogas.

2013: Abstenção da votação da PEC das Domésticas; Não à PEC 37, que reduzia os poderes do Ministério Público; e Não ao fim do voto secreto nas sessões das casas do Legislativo

2014: Não à 'Lei das Palmadas', que proibia os pais de punirem e castigarem fisicamente os filhos (crianças e adolescentes) e Não ao Marco Civil da Internet.

2015: aprovou sua primeira emenda constitucional, referente à impressão do voto após uso da urna eletrônica; Não ao fim do voto obrigatório e Sim ao financiamento empresarial de campanha

2016: Sim ao impeachment de Dilma Rousseff; Não à anistia ao 'caixa 2'; Sim à abertura do pré-sal ao capital estrangeiro; Sim à PEC 241, que estipulou teto para os gastos públicos por 20 anos; abstenção na lei da terceirização geral.

\section{NOTAS}

1. Integram o corpus: 1986 - 'O salário está baixo'/ Veja (3/9/86); 1997 - Câmera Aberta/ Record (35:39); 1999 - Câmera Aberta/ Record (23/5/99 - 53:19); 2000 - IstoÉ Gente (14/2/00); 2003 Discussão com Maria do Rosário /Rede TV (2:19); 2011 - Programa do Jô/Globo (22:24); 2011 Playboy (29/6/11); 2011 - CQC/ Band (5:55); 2011 - 'Comissão da Inverdade'/Folha de São Paulo (11/1/11); 2012 - 'Contra a Lei que proíbe dar palmadas'/O Dia (9/1/12); 2011 - Época (2/7/11); 2012 - Brasil em Discussão/Record News (13/5/12 -56:04); 2012 - Agora é Tarde/ Band (32:12); 
2013 - Época (18/10/13); 2013 - Documentário com Stephen Fry/ BBC (12:53); 2014 - El País (14/2/14); 2014 - 'Censura Escancarada'/ FSP (3/4/14); 2014 - Infomoney (22/5/14); 2014 - Zero Hora (10/12/14); 2015 - Mariana Godoy Entrevista - Rede TV (3/7/15 - 41:03); 2015 - Correio Braziliense (15/11/15); 2015 - Jornal Opção (21/9/15 5:05); 2016 - Programa do Ratinho/SBT (6/3/16 - 43:16); 2016 -The New York Times (24/3/16 - vídeo - 1:16:26); 2017 - FSP (13/3/17); 2017 -Veja (22/7/17).

2. Ver Revista Veja, 28/11/87, p. 40-41. Pôr bombas nos quartéis, um plano na Esao, p. 40-41.

3. Partido político que governou o Brasil de 2003 a 2016.

4. Ver matéria da Folha de São Paulo, 06/06/18. https://www1.folha.uol.com.br/poder/2018/06/ maioria-do-stf-suspende-voto-impresso-nas-eleicoes.shtml. Consultado em 11/04/19.

5. Casos que resultaram em processos de cassação: declaração pelo fechamento do Congresso (1993); agressão verbal contra o ministro Luiz Carlos Bresser-Pereira, a quem chamou de "ladrão dos servidores" (1995); declaração pelo fuzilamento do presidente Fernando Henrique Cardoso (1999); agressão verbal à senadora Marinor Brito (PSOL), a quem chamou de "heterofóbica" e disse, com conotação sexual, que ela não o interessava por ser "muito ruim" (2011); agressão verbal e apologia ao estupro à deputada Maria do Rosário (PT), ao repetir que ela não merecia ser estuprada porque era feia (2014); ofensa à presidenta Dilma Rousseff, ao homenagear o coronel e torturador Carlos Alberto Brilhante Ustra (2016), etc.

6. Entrevista disponibilizada também na versão online da revista. Ver http:// revistaepoca.globo.com/Revista/ Epoca/0,EMI245890-15223,00JAIR+BOLSONARO+SOU+PRECONCEITUOSO+COM+MUITO+ ORGULHO.html. Acesso em 10/06/16.

7. Entrevista disponível em https://www.youtube.com/watch?v=uLEpbTwW2MI. Acesso em 10/02/16.

8. Veja, 1986, artigo “O salário está baixo". Disponível em https://veja.abril.com.br/blog/reveja/ o-artigo-em-veja-e-a-prisao-de-bolsonaro-nos-anos-1980/. Acesso em 16/05/17.

9. Disponível em https://www1.folha.uol.com.br/poder/2017/03/1865771-nao-e-a-imprensa-ouo-stf-que-vai-falar-o-limite-pra-mim-diz-bolsonaro.shtml. Acesso em 20/03/17.

10. Entrevista disponível em https://www.youtube.com/watch?v=Y3TM27bxvsE. Acesso em 01/03/17.

11. Disponível em https://www.correiobraziliense.com.br/app/noticia/politica/2015/11/15/ interna_politica, 506556/cunha-nao-se-safa-dessa-afirma-jair-bolsonaro-em-entrevista.shtml

12. Disponível em https://www.infomoney.com.br/politica/se-eu-nao-for-candidato-quero-service-de-aecio-diz-jair-bolsonaro/. Acesso em 20/03/16.

13. Disponível em https://gauchazh.clicrbs.com.br/politica/noticia/2014/12/bolsonaro-diz-quenao-teme-processos-e-faz-nova-ofensa-nao-merece-ser-estuprada-porque-e-muito-feiacjkf8rj3x00cc01pi3kz6nu2e.html. Acesso em 20/03/16.

14. Habitantes de comunidades negras rurais formadas por descendentes de africanos escravizados, que vivem, em sua maioria, da agricultura de subsistência em terras doadas, compradas ou ocupadas há bastante tempo. Fonte: Fundação Joaquim Nabuco.

15. Entrevista disponível em https://www.youtube.com/watch?v=a-5HGYofvLo. Acesso em 01/03/17.

16. Mensalão e Petrolão são escândalos de corrupção que abalaram os governos do PT.

17. Áudio da entrevista disponível em https://exame.abril.com.br/brasil/bolsonaro-chamarefugiados-de-escoria-do-mundo/. Acesso em 30/09/19.

18. Entrevista disponível em https://www.youtube.com/watch?v=CiF-KhPqes8. Acesso em 01/03/16.

19. Entrevista disponível em https://www.youtube.com/watch?v=gyAb-vHMR5g. Acesso em 10/03/16.

20. IstoÉ Gente, 2000.

21. IstoÉ Gente, 2000. 
22. Playboy, 2011.

23. Programa do Ratinho, 2014.

24. IstoÉ, 2000; Playboy, 2011; Programa do Ratinho, 2014; Brasil em Discussão, 2012; El País, 2014; Mariana Godoy Entrevista, 2015; The New York Times, 2016; Folha de São Paulo, 2017.

25. Arquivo online da revista. Ver http://www.terra.com.br/istoegente/28/reportagens/ entrev_jair.htm. Acesso em 01/03/16.

26. Câmera Aberta, 1999; Programa do Jô, 2005; Playboy, 2011; Brasil em Discussão, 2012; Época, 2013; Programa do Ratinho, 2014; El País, 2014; The New York Times, 2016; Folha de São Paulo, 2017.

27. Época 2011; Playboy, 2011; Mariana Godoy Entrevista, 2016.

28. Câmera Aberta, 1997.

29. CQC, 2011; Época, 2011; Folha de São Paulo, 2017.

30. Ver http://br.rfi.fr/franca/20160406-le-pen-e-condenado-por-dizer-que-camaras-de-gas-doholocausto-foram-detalhe-0.

31. Na sessão de impeachment de Dilma Rousseff, em 2016.

\section{RESUMOS}

Este artigo analisou discursos do político Jair Bolsonaro em meios de comunicação, de 1986 a 2017, bem como sua atuação política no Parlamento, com o objetivo de identificar as maneiras como esse ator insere os temas do nacionalismo, xenofobia, racismo, Estado forte e antidemocracia no debate público, relacionando os achados com a teoria do radicalismo de direita. A pesquisa identificou que ele manifesta posições bem demarcadas contra pessoas nãobrancas -negros, índios e quilombolas - e contra imigrantes - sobretudo os pobres -, bem como defende modelos de Estado e sociedade baseados no militarismo, na supervalorização da lei e da ordem e na fragilização dos direitos humanos, impondo determinados paradoxos às instituições e princípios democráticos.

This article analyzes Jair Bolsonaro's speeches in the media from 1986 to 2017, as well as his political activities in Parliament, in order to identify the ways in which this actor inserts the themes of nationalism, xenophobia, racism, antidemocracy in the public debate, relating the findings to the theory of radical right. The research identified that he shows well-demarcated positions against non-white people - blacks, Indians and quilombolas - and against immigrants especially the poor - as well as defending models of state and society based on militarism, overvaluation of law and order and in the weakening of human rights, imposing certain paradoxes on democratic institutions and principles.

Cet article analyse les discours de Jair Bolsonaro dans les médias de 1986 à 2017, ainsi que ses activités politiques au Parlement, afin d'identifier les moyens par lesquels cet acteur insère les thèmes du nationalisme, de la xénophobie, du racisme, d'un État fort et de l'anti-démocratie dans le débat public, reliant les résultats à la théorie du radicalisme de droite. La recherche a révélé qu'il montrait des positions bien démarquées à l'égard des personnes non blanches - Noirs, Indiens et Quilombolas - et des immigrés - en particulier des pauvres - tout en défendant des modèles d'État et de société fondés sur le militarisme, la surévaluation de l'ordre public dans 
l'affaiblissement des droits de l'homme, imposant certains paradoxes aux institutions et principes démocratiques.

Este artículo analiza los discursos del político Jair Bolsonaro en medios de comunicación de 1986 a 2017, así como su actuación política en el Parlamento, con el objetivo de identificar las maneras cómo ese actor inserta los temas del nacionalismo, la xenofobia, el racismo, el Estado fuerte y la (anti) democracia en el debate público, relacionando los hallazgos con la teoría del radicalismo de derecha. La investigación identificó que él manifiesta posiciones bien demarcadas contra personas no blancas -negros, indios y quilombolas- y contra inmigrantes -sobre todo los pobres-, así como defiende modelos de Estado y sociedad basados en el militarismo, en la sobrevaloración de la ley y del orden y en la fragilización de los derechos humanos, imponiendo determinadas paradojas a las instituciones y principios democráticos.

ÍNDICE

Palabras claves: radicalismo de derecha, derechas brasileñas, Jair Bolsonaro, democracia Mots-clés: radicalisme de droite, droits brésiliens, Jair Bolsonaro, démocratie

Palavras-chave: radicalismo de direita, direitas brasileiras, Jair Bolsonaro, antidemocracia Keywords: right-wing radical, Brazilian rights, Jair Bolsonaro, antidemocracy

\section{AUTORES}

\section{EDSON DALMONTE}

Edson Dalmonte é doutor em Comunicação e professor do Programa de Pós-Graduação em Comunicação e Cultura Contemporâneas da Universidade Federal da Bahia (UFBA). E-mail: edsondalmonte@gmail.com

\section{PRISCILLA DIBAI}

Priscilla Dibai é doutoranda no Programa de Pós-Graduação em Comunicação e Cultura Contemporâneas da Universidade Federal da Bahia (UFBA) e mestra em Ciências Sociais, também pela UFBA. E-mail: pdibai@gmail.com 